\title{
Direitos fundamentais das crianças nas produções sobre formação de professores da educação infantil: uma análise à luz da teoria histórico- cultural
}

\author{
Fundamental rights of children in productions on the teacher education of \\ childhood education: an analysis according to the cultural-historical theory
}

Marília Alves dos Santos ${ }^{1}$
Ariadni da Silva de Oliveira
Elieuza Aparecida de Lima $^{3}$

\section{Resumo}

A Educação Infantil é um direito fundamental da criança assegurado pela Constituição brasileira desde 1988 e reafirmado pelo Estatuto da Criança e do Adolescente de 1990. No ambiente educacional os professores são um dos principais responsáveis pela garantia dos direitos fundamentais das crianças, o que torna necessário pensar a formação de educadores com vistas a garantir que os mesmos respeitem e assegurem tais direitos. O objetivo deste artigo é analisar se e como as produções sobre formação de professores da Educação Infantil discutem os direitos fundamentais das crianças e tecer contribuições, à luz da Teoria Histórico-Cultural para se pensar os direitos das crianças, a partir das discussões apresentadas pelos textos analisados. Foram selecionados onze artigos científicos localizados no Portal de Periódicos da CAPES por meio dos descritores "formação de professores", "formação de educadores" e "educação infantil". Dos artigos lidos, somente cinco se referiram diretamente aos direitos das crianças, principalmente para defendê-las como sujeitos de direito à educação. Os demais elementos apresentados pelos textos foram organizados e discutidos a partir de seis categorias: o direito a serem educados por professores com formação de qualidade; o direito a serem cuidados com atenção e afeto; o direito à liberdade de expressão, respeito e valorização da diversidade; os direitos das crianças com deficiência e com dificuldades de aprendizagem; o direito à brincadeira e liberdade; o direito ao desenvolvimento humano. Em se tratando de produções sobre formação de professores da/para a Educação Infantil, compreendemos como imprescindível o comprometimento ético e científico dos educadores e o respeito ao processo educativo, às crianças e aos seus direitos fundamentais.

Palavras-chave: Educação Infantil; Direitos fundamentais das crianças; Formação de professores.

\footnotetext{
Abstract

${ }^{1}$ Psicóloga e mestranda no Programa de Pós-Graduação em Psicologia do Desenvolvimento e Aprendizagem (UNESP/Bauru) - email: marilia.santos@unesp.br

${ }^{2}$ Pedagoga e mestranda no Programa de Pós-Graduação em Educação (UNESP/Marília) - email: ariadni.so@gmail.com

${ }^{3}$ Docente no curso de Pedagogia (UNESP/Marília) e no Programa de Pós-Graduação em Educação

(UNESP/Marília) - email: aelislima2013@gmail.com
}

Revista Devir Educação, Lavras, vol.3, n.2, p.114-135 jul./dez., 2019. 


\section{OO DEVIR EDUCAÇÃO \\ ISSN: 2526-849X}

Childhood Education is a fundamental right of the child ensured by the Brazilian Constitution since 1988 and reaffirmed by the Statute of the Child and Adolescent of 1990. In the educational environment teachers are one of the main responsible for guaranteeing children's fundamental rights, which makes it necessary to think the teachers education with a view to ensuring that they respect and ensure such rights. The purpose of this article is to analyze if and how the productions on teacher education in Childhood Education discuss the fundamental rights of children and make contributions according to the Cultural-Historical Theory. Eleven scientific articles were selected from the Portal of Periodicals of CAPES through the descriptions "teacher education", "educator education" and "childhood education". From read articles, only five referred directly to children's rights, mainly to defend them as subjects of right to education. The other elements presented by the texts were organized and discussed in six categories: the right to be educated by qualified teachers; the right to be cared with attention and affection; the right to freedom of expression, respect and appreciation of diversity; the rights of children with disabilities and learning difficulties; the right to play and freedom; the right to human development. When it comes to productions on teacher education for children, we understand how essential is the ethical and scientific commitment of educators and respect for the educational process, for children and their fundamental rights.

Keywords: Child education; Fundamental rights of children; Teacher education

\section{Introdução}

Inicialmente concebida como uma política de caráter assistencialista e compensatória, a educação escolar de crianças pequenas no Brasil tinha por objetivo suprir carências culturais e sociais dos educandos das classes mais desfavorecidas e marginalizadas da sociedade (FEBRONIO, 2011; GUIMARÃES; ARENHART; SANTOS, 2017). Guimarães, Arenhart e Santos (2017) explicam o movimento iniciado somente ao final dos anos 1990 de construção de uma "Pedagogia da Educação Infantill" que buscava romper com o modelo assistencialista e remediador e instaurar uma organização escolar comprometida com o desenvolvimento das crianças pequenas segundo suas particularidades e reais necessidades. No entanto, Coutinho (2017) aponta que a Educação Infantil (EI) em nosso país, sobretudo das crianças de zero a três anos, ainda é marcada por um ideário que a vincula ao assistencialismo. Para Oliveira (2006, p. 116), essa etapa do ensino é vista, muitas vezes, como mera "extensão do lar", como uma forma de compensação social e econômica na qual a criança apenas receberá cuidados referentes à alimentação e higiene, mas não como um espaço formativo e educativo.

Sobre tal compreensão reducionista, Cardoso (2016, p. 157) alerta: “A escola, que se coloca como simples extensão da família corre o risco de - com o propósito de socialização -

Revista Devir Educação, Lavras, vol.3, n.2, p.114-135 jul./dez., 2019. 


\section{OO DEVIR EDUCAÇÃO}

ISSN: 2526-849X

padronizar o comportamento das crianças e transpor as relações de identidade, próprias da esfera familiar, para a convivência escolar". Aquino (2015), por sua vez, destaca a compreensão - preocupante - da EI como etapa preparatória para o Ensino Fundamental (EF), passando a reproduzir uma organização conteudista, fragmentada em disciplinas, com acentuada ênfase no processo de alfabetização e que ignora as especificidades do desenvolvimento infantil e das necessidades das crianças.

Todavia, a EI é responsável por muito mais que o cuidado físico da criança: ela é um espaço/tempo de promoção do desenvolvimento integral de seus educandos - físico, psicológico, social, do caráter, das capacidades cognitivas, dentre outros (OLIVEIRA, 2006; FEBRONIO, 2011) - e, sobretudo, é um Direito Fundamental da Criança (DFC) assegurado pela legislação brasileira desde 1988. A Constituição da República Federativa do Brasil (BRASIL, 1988; 2016) assegura, em seu Artigo 205, a educação como direito de todos e dever do Estado; em específico, no Artigo 208, inciso IV, o documento garante o direito de crianças pequenas à EI por meio de creches e pré-escolas. Em 1990, o Estatuto da Criança e do Adolescente - ECA (BRASIL, 1990; 2017) reafirma, em especial nos seus Artigos 53 e 54, a educação promotora de desenvolvimento como direito das crianças e adolescentes e dever do Estado.

Em 1995, o Ministério da Educação, por meio da Secretaria de Educação Básica, publica a primeira edição do documento Critérios para um atendimento em creches que respeite os direitos fundamentais das crianças ${ }^{4}$ (CAMPOS; ROSEMBERG, 1995; 2009), documento este que define diretrizes para a organização e atuação de educadores em creches e demais instituições de EI que respeitem os DFC. No entanto, mesmo com toda a legislação e diretrizes precedentes, é somente em 1996, com a Lei de Diretrizes e Bases da Educação Nacional (BRASIL, 1996) que a EI é definida como a primeira etapa da Educação Básica nacional, configurando um importante marco para a garantia e promoção dos Direitos Fundamentais das Crianças.

Entendendo que, no ambiente educacional, são os professores e demais profissionais da educação os responsáveis pela garantia dos DFC, bem como pela promoção do desenvolvimento humano, Vicentini e Barros (2017, p. 173) defendem o professor como "o responsável por a escola ser a força motriz no processo de apropriação do conhecimento e das máximas qualidades humanas pela criança, tornando-a um ser verdadeira e completamente

\footnotetext{
${ }^{4}$ Neste trabalho, a fim de simplificar a referência a esse documento, utilizamos a abreviação "CACRDFC".
} 


\section{QD DEVIR EDUCAÇÃO \\ ISSN: 2526-849X}

humano". Nesse sentindo, entendemos a necessidade e importância de se pensar a formação inicial e continuada de educadores com vistas a garantir que esses profissionais respeitem e assegurem, em suas práticas educativas, os DFC.

Tendo como estofo teórico e metodológico o Materialismo Histórico-Dialético, a Teoria Histórico-Cultural tem sido uma teoria de destaque no cenário educacional brasileiro para o estudo e proposição de modos de organização da EI (AQUINO, 2015; BARROS; PEQUENO, 2017; VICENTINI; BARROS, 2017) e da formação de professores (SOUZA; MOURA, 2015; DE MARCO; LIMA, 2017; MENDONÇA, 2017) que considerem as especificidades e necessidades das crianças e promovam o desenvolvimento infantil.

Para a Teoria Histórico-Cultural, as instituições de EI, para muito além de locais de cuidado físico das crianças, são responsáveis pela promoção do desenvolvimento humano por meio da transmissão sistematizada dos conhecimentos científicos objetivados pelos homens e acumulados ao longo da história da humanidade num movimento dialético de cuidadoeducação (PASQUALINI, 2016; BARROS; PEQUENO, 2017). De acordo com Vicentini e Barros (2017, p. 173), "O papel da escola infantil a partir do Materialismo Histórico Dialético e da Teoria Histórico-Cultural nos auxilia a compreender este espaço como lugar privilegiado no desenvolvimento e aprendizagem da criança pequena, pois contribui para a sua humanização". Essa compreensão afiança a defesa de que, as práticas educativas na EI, assim como em qualquer outro espaço educacional, devem se orientar à transformação das funções psicológicas elementares em funções psicológicas superiores ${ }^{5}$, exclusivamente humanas (tais como atenção e memória voluntárias, linguagem intelectual e pensamento verbal, imaginação, dentre outras). Pasqualini (2016) argumenta sobre o valor da organização de situações pedagógicas respeitando as possibilidades das crianças e tendo em vista a atividade-guia ${ }^{6}$ do período em que cada educando se encontra (no caso da EI, a comunicação emocional direta, a atividade objetal manipulatória ou o jogo de papéis).

A formação de professores, compreendida a partir da Teoria Histórico-Cultural (THC), deve conferir ao profissional da educação os elementos necessários para a articulação entre a teoria apropriada, a realidade apreendida e a prática empreendida. Nesse sentido, o principal desafio posto à THC ao pensar a formação docente é articular uma formação que promova o desenvolvimento da consciência do professor - lhe possibilitando a apreensão da realidade

\footnotetext{
${ }^{5}$ Não sendo objetivo do presente trabalho definir e discorrer sobre os conceitos de funções psicológicas elementares e superiores, sugerimos para maior compreensão a leitura de Martins (2011). ${ }^{6}$ Sobre atividade-guia e periodização do desenvolvimento sugerimos a leitura de Facci (2004).
}

Revista Devir Educação, Lavras, vol.3, n.2, p.114-135 jul./dez., 2019. 


\section{QD DEVIR EDUCAÇÃO \\ ISSN: 2526-849X}

escolar em seu movimento, pela mediação do pensamento abstrato (superação da aparência imediata ruma à essência do fenômeno) - ao passo que também garanta ao educando uma formação humanizadora (MENDONÇA, 2017). Nessa perspectiva, Martins (2009) defende uma formação de professores que revele a historicidade, a totalidade e as contradições inerentes aos fenômenos escolares e educacionais. Nas palavras da autora:

Defendemos, portanto, uma formação de professores que seja, por um lado, via de formação profissional, determinante da aprendizagem de um conjunto de conhecimentos e domínios teóricos, metodológicos e técnicos e, por outro, via estruturante de recursos afetivo-cognitivos imprescindíveis para que os futuros professores (ou professores em formação contínua) possam conhecer com o devido rigor, cientificidade e criticidade não apenas as dimensões técnicas próprias ao seu exercício profissional mas, sobretudo, as condições histórico-sociais nas quais esse exercício ocorrerá e que precisam ser transformadas. (MARTINS, 2009, p. 455).

Tendo em vista o exposto, o objetivo do presente trabalho é analisar se e como as produções sobre formação de professores da Educação Infantil discutem os direitos fundamentais das crianças e, posteriormente, tecer contribuições, à luz da Teoria HistóricoCultural, para se pensar os direitos das crianças a partir das discussões apresentadas pelos textos analisados.

\section{Percurso metodológico}

A busca pelas produções sobre formação de professores da educação infantil deu-se no Portal de Periódicos da CAPES. Os descritores utilizados - que deveriam estar presentes no título do trabalho - foram "formação de professores", "formação de educadores" e "educação infantil". Como especificidades da busca, definimos produções publicadas de 1996 (considerando ser o ano em que a EI passou a ser a etapa inicial da Educação Básica, como discutido na Introdução do trabalho) a 2018 (ano da realização da pesquisa), somente no formato de artigo e escritas em língua portuguesa. Inicialmente, com os descritores "formação de professores" e "educação infantil" encontramos 18 produções, sendo a mais antiga do ano 
de 2006, e com os descritores "formação de educadores" e "educação infantil" encontramos apenas um artigo, datado de 2014. Não foi encontrado nenhum artigo publicado entre 1996 e 2005.

Definimos como especificidade da busca o formato exclusivo de artigo e, embora tenhamos encontrado dois resumos publicados em anais de eventos científicos e uma resenha de livro sobre a temática investigada, eles foram excluídos de nossa análise. Desse modo, os critérios de exclusão foram: produções em formatos diferentes de artigo científico; produções publicadas em revistas exclusivamente internacionais ou em revistas nacionais de qualis igual ou inferior a B3 (quadriênio 2013-2016); revisões de literatura; estudos comparativos entre Brasil e outros países. A relação final das produções analisadas é apresentada no Quadro 1.

Quadro 1 - Relação final de artigos analisados referentes a formação de professores da Educação Infantil Marília/SP - 2019.

\begin{tabular}{|c|c|c|}
\hline Ano & Título & Autores \\
\hline \multicolumn{3}{|c|}{ Descritores: "formação de professores" + "educação infantil" } \\
\hline 2006 & $\begin{array}{l}\text { A formação de professores para a educação infantil: desafios } \\
\text { para a universidade }\end{array}$ & Rubia-Mar Nunes PINTO \\
\hline 2006 & $\begin{array}{c}\text { Formação de professores, competências e saberes para a } \\
\text { atividade docente na educação infantil }\end{array}$ & $\begin{array}{l}\text { Joana Angélica Bernardo de } \\
\text { OLIVEIRA }\end{array}$ \\
\hline 2006 & $\begin{array}{l}\text { Formação identitária dos professores de educação infantil: } \\
\text { compreensão acerca do trabalho docente }\end{array}$ & Tatiane Dalpério TONINATO \\
\hline 2011 & $\begin{array}{c}\text { Formação inicial de professores de educação infantil: que } \\
\text { formação é essa? }\end{array}$ & Maria da Paixão Gois FEBRONIO \\
\hline 2011 & $\begin{array}{c}\text { A formação de professores para a Educação Inclusiva: alguns } \\
\text { aspectos de um trabalho colaborativo entre pesquisadores e } \\
\text { professores da Educação Infantil }\end{array}$ & $\begin{array}{l}\text { Claudia Regina Mosca GIROTO e } \\
\text { Rosane Michelli de CASTRO }\end{array}$ \\
\hline 2012 & $\begin{array}{l}\text { Formação de professores, educação infantil e diversidade } \\
\text { étnico-racial: saberes e fazeres nesse processo }\end{array}$ & Lucimar Rosa DIAS \\
\hline 2015 & $\begin{array}{c}\text { Formação de professores para a educação infantil: a } \\
\text { integração necessária entre educação e cuidado para uma } \\
\text { práxis pedagógica emancipatória }\end{array}$ & $\begin{array}{l}\text { Sandra Regina Mantovani LEITE e } \\
\text { Alonso Bezerra de CARVALHO }\end{array}$ \\
\hline 2017 & $\begin{array}{l}\text { Formação de professores da educação infantil: reflexões sobre } \\
\text { a necessária instrumentalização teórica do profissional atuante } \\
\text { com crianças com ou sem deficiência }\end{array}$ & $\begin{array}{c}\text { Gabriely Cabestré AMORIM, } \\
\text { Elieuza Aparecida de LIMA e Rita } \\
\text { de Cássia Tibério ARAÚJO }\end{array}$ \\
\hline 2017 & $\begin{array}{l}\text { Educação infantil pós-LDB/1996: formação inicial de } \\
\text { professores e práticas pedagógicas }\end{array}$ & $\begin{array}{c}\text { Daniela de O. GUIMARÃES, Deise } \\
\text { ARENHART e Nubia de Oliveira } \\
\text { SANTOS }\end{array}$ \\
\hline 2017 & $\begin{array}{l}\text { A formação continuada de professores da educação infantil } \\
\text { em Sorocaba/SP }\end{array}$ & Meira Chaves PEREIRA \\
\hline \multicolumn{3}{|c|}{ Descritores: "formação de educadores" + "educação infantil" } \\
\hline 2014 & $\begin{array}{c}\text { Integração Saúde e Educação: Contribuições da Psicologia } \\
\text { para a Formação de Educadores de uma Creche em } \\
\text { Sexualidade Infantil }\end{array}$ & $\begin{array}{c}\text { Adriane Costa e Rocha CIAFFONE } \\
\text { e Marivete GESSER }\end{array}$ \\
\hline
\end{tabular}
Fonte: Das autoras (2019). 


\section{QD DEVIR EDUCAÇÃO \\ ISSN: 2526-849X}

Para contemplar o objetivo definido buscamos, em nossa análise, responder a três perguntas orientadoras: 1. O texto faz referência aos DFC? 2. Se sim, quais as análises e discussões feitas pelas autoras referentes a esses direitos? 3. Além das referências diretas, quais os outros elementos apresentados ao longo do artigo nos ajudam a pensar e refletir sobre os DFC? Respondemos a essas perguntas buscando levantar contribuições a partir da Teoria Histórico-Cultural e tendo em vista os direitos das crianças e adolescentes assegurados pelo ECA (BRASIL, 1990; 2017) e as diretrizes para a organização das instituições de EI e atuação dos educadores descritos pelo documento CACRDFC (CAMPOS; ROSEMBERG, 1995; 2009).

\section{Discussão}

Dos 11 textos analisados somente 5 se referem diretamente aos direitos das crianças, sendo eles os artigos de autoria de: Oliveira (2006), Febronio (2011), Leite e Carvalho (2015), Amorim, Lima e Araújo (2017) e Guimarães, Arenhart e Santos (2017). Embora não aprofundem na discussão dos DFC, os textos enfatizam a criança como sujeito de direitos e, em especial, como sujeito de direito à educação.

Oliveira (2006) defende a EI como um direito não apenas da criança, mas também de seus cuidadores e ressalta a importância de uma formação docente para atuação com crianças pequenas que garanta a articulação entre teoria e prática. Febronio (2011), além de pontuar a importância de uma formação sólida de professores como direito das crianças, assume que para que o direito da criança à educação se efetive é necessário aos professores

[...] conhecer esse território de trabalho, de conquistas e de pesquisa; reconhecer a nós mesmos [professores] como pessoa e profissional que se inserem nesse contexto e, também, buscar aprimorar-nos profissionalmente e constantemente, para que, com sabedoria, possamos intervir no processo complexo que envolve seu fazer diário: o de ensinar e de aprender. (FEBRONIO, 2011, p. 156).

Leite e Carvalho (2015) ressaltam a necessidade de o professor compreender seus educandos como sujeitos sociais, culturais, singulares e, sobretudo, detentores de diretos, destacando o direito da criança em ser cuidada e acolhida pelo professor e pela instituição. De 


\section{OO DEVIR EDUCAÇÃO}

ISSN: 2526-849X

modo semelhante, Guimarães, Arenhart e Santos (2017, p. 377) enfatizam a compreensão das especificidades da EI a partir das necessidades das crianças e não da rigidez conteudista, apontando as crianças como "sujeitos de direto à expressão, à brincadeira, às relações dialógicas”. Amorim, Lima e Araújo (2017) são as únicas a ressaltar o direito das crianças com deficiência de estarem inseridas em turmas comuns e fazendo uso do Atendimento Educacional Especializado (AEE), “cujo objetivo é eliminar as barreiras de aprendizagem e arquitetônicas que possam existir no meio em que estão inseridas" (AMORIM; LIMA; ARAÚJO, 2017, p. 389).

Os demais artigos selecionados foram organizados em 6 categorias: o direito das crianças de serem educadas e cuidadas por professores com formação de qualidade; o direto das crianças a serem cuidadas com atenção e afeto; o direito das crianças à liberdade de expressão, respeito e valorização da diversidade étnico-cultural; os direitos das crianças com deficiência e com dificuldades de aprendizagem; o direito das crianças à brincadeira e à liberdade; o direito das crianças ao desenvolvimento humano. A partir dessas categorias, os artigos serão apresentados e discutimos à luz da Teoria Histórico-Cultural, tendo em vista os direitos descritos no ECA (BRASIL, 1990) e nas diretrizes presentes no documento CACRDFC (CAMPOS; ROSEMBERG, 1995, 2009).

Em relação ao direito a serem educadas e cuidadas por professores com formação de qualidade, Oliveira (2006) aponta como a formação de professores da EI é restrita e insuficiente no que se refere à articulação entre teoria e prática, denunciando-a como formação conteudista e que impede à criança desenvolver-se em suas máximas possibilidades. A autora defende o valor de uma formação que ensine os pressupostos do desenvolvimento infantil e que possibilite ao professor refletir sua própria prática como um direito da criança. De modo semelhante, Leite e Carvalho (2015) também defendem uma formação de educadores para a EI que seja teoricamente sólida e coerente; que priorize as especificidades do trabalho com crianças pequenas (0 a 6 anos); que contemple as diversas dimensões do desenvolvimento infantil - epistemológica, psicológica, ética e estética; que confira ao professor elementos para concretizar um ensino emancipador; e que, sobretudo, priorize "a democracia no espaço educativo e nas relações humanas" (LEITE; CARVALHO, 2015, p. 920). Amorim, Lima e Araújo (2017) enfatizam o valor de uma formação que promova o desenvolvimento da consciência do professor e que seja capaz de orientar sua atuação nos diversos contextos de sua prática profissional.

Revista Devir Educação, Lavras, vol.3, n.2, p.114-135 jul./dez., 2019. 


\section{QD DEVIR EDUCAÇÃO \\ ISSN: 2526-849X}

Guimarães, Arenhart e Santos (2017) trazem contribuições ao discutirem o papel do estágio na formação de professores para EI. As autoras definem como momento de aproximação à realidade educacional concreta e como espaço de discussão e construção da identidade docente, ou seja, "espaço de fundamentação teórica, produção de conhecimento, diálogo e consideração de possibilidades de intervenção na realidade" (GUIMARÃES; ARENHART; SANTOS, 2017, p. 368). Todavia, Febronio (2011) apresenta um contraargumento à definição dessas autoras e alega que os estágios são pouco planejados, tornando a formação de professores da EI bastante restrita e insuficiente nas possibilidades de articulação entre teoria e prática.

Giroto e Castro (2011) defendem o lugar da aprendizagem e da livre expressão para o desenvolvimento das crianças e entendem ser necessário garantir aos professores - já formados e em formação - um ensino verdadeiramente científico a respeito das dificuldades de aprendizagem, do processo de alfabetização e suas singularidades e do crescente fenômeno de patologização e medicalização da infância.

Dias (2012), também assumindo a necessidade de respeito à liberdade de expressão pelos educandos, discute a diversidade como tema da formação de professores:

Os cursos de formação de professores para a educação infantil devem possibilitar que estes sejam capazes de desenvolver experiências de aprendizagem nas quais as crianças se apropriem dos conhecimentos culturais e científicos produzidos pelos vários grupos étnico-raciais, especialmente negros e indígenas. E isso por meio de experiências com filmes, danças, arte, música, teatro entre outras linguagens que tragam os saberes científicos, as lutas e resistência desses povos. (DIAS, 2012, p. 668).

Pinto (2006) busca demonstrar como as políticas educacionais propostas contrariam e negam, muitas vezes, as contribuições acadêmicas de pesquisadores da educação, se articulando a uma perspectiva de aprofundamento da exclusão social. Nesse sentido, a autora denuncia a formação de professores voltada exclusivamente para a inserção no mercado e não para a promoção do desenvolvimento humano. Pereira (2017), por fim, discute o histórico e as diretrizes legais para formação continuada de professores da EI tendo em vista os documentos oficiais nacionais, conferindo destaque aos Artigos 61 e 62 da LDB (Lei 9.394/96) - que dispõem sobre a formação dos profissionais da educação -, às Diretrizes 


\section{OO DEVIR EDUCAÇÃO}

ISSN: 2526-849X

Curriculares Nacionais para a Formação Inicial e Continuada dos Profissionais do Magistério da Educação Básica (CNE/CP n²/2015) e às Metas 15 e 16 do Plano Nacional de Educação (2014-2024) - que dispõem sobre a formação em nível superior e formação continuada, respectivamente, dos professores da Educação Básica.

As discussões apresentadas acima denunciam as práticas de formação descompromissadas com a humanização e reduzidas a mercadorias, mas também evidenciam a importância, para as crianças, de uma formação que possibilite ao professor compreender a realidade de sua sala de aula em suas múltiplas determinações, de uma formação que o permita articular teoria e prática, garantindo o desenvolvimento de sua própria consciência e promovendo a superação das funções elementares pelas funções psicológicas superiores em seus educandos. Como defende Martins (2009, p. 470), a formação de professores deve, portanto, se orientar à consolidação de uma práxis educativa crítica, intencional, consciente e "a serviço da emancipação humana". Nesse sentindo, concordamos com Febronio (2011) sobre a formação de professores ser, sobretudo, um direito fundamental das crianças. Tal direito é assegurado pelos Artigos 53 e 54 do ECA (BRASIL, 1990; 2017) - que dispõem, respectivamente, sobre o direito à educação e desenvolvimento e sobre o dever do Estado de assegurar o atendimento em creches e pré-escolas - e é descrito também no documento CACRDFC (CAMPOS; ROSEMBERG, 1995; 2009) como políticas de creche que respeita os DFC e que reconhece o direito das crianças de ampliarem seus conhecimentos.

$O$ direito a serem cuidadas com atenção e afeto: Trazendo em sua discussão uma análise do histórico da concepção de infância em nossa sociedade, Toninato (2006) explica que, ao longo de alguns séculos, a criança fora compreendida como um pequeno adulto, um sujeito de pouca idade e características adultizadas. Segundo a pedagoga, mesmo com o avanço nas discussões acerca das especificidades da EI e com o avanço na formação dos profissionais, ainda é possível observar educadores que reproduzem tais concepções e entendem a criança como um "ser em miniatura" que necessita apenas de cuidados referentes à higiene e alimentação, de modo que o educando acaba por ter suas necessidades de afeto e relações sociais negligenciadas.

Segundo Guimarães, Arenhart e Santos (2017), muitas vezes a relação das crianças com os educadores pode ser prejudicada devido a práticas automatizadas, mecânicas, meramente instrumentais e descontextualizadas, em que os professores, devido ao pouco tempo e à necessidade de cuidado de grande quantidade de educandos, acabam dificultando e

Revista Devir Educação, Lavras, vol.3, n.2, p.114-135 jul./dez., 2019. 


\section{OO DEVIR EDUCAÇÃO}

ISSN: 2526-849X

desestimulando os atos comunicativos e exploratórios das crianças pequenas. Em consonância com essas ideias, Leite e Carvalho (2015) defendem a função pedagógica do cuidado com as crianças como fundamento essencial do trabalho na EI uma vez que os pequenos vivenciam um período da vida em que ainda são predominantemente dependentes dos cuidados providos pelos adultos. Nesse sentido, as autoras argumentam que cuidado não se refere exclusivamente às necessidades relacionadas ao corpo, mas ao conjunto de necessidades relacionadas à alimentação, higiene, segurança, afeto, brincadeiras, saúde, ética e, sobretudo, educação.

Pelo apontado, é possível notar situações de negligência nos cuidados com a criança, principalmente em relação à dimensão afetiva do cuidar. Para a Teoria Histórico-Cultural, afeto e cognição constituem uma unidade dialética, ou seja, são dimensões interiores uma a outra, internamente articuladas entre si (MARTINS, 2011; GOMES, 2014). Conforme explicar Martins (2011, p. 210):

$\mathrm{Na}$ atividade que vincula o ser à natureza [...] encontra-se sintetizada sua capacidade para representar o mundo afetivo-cognitivamente. Assim, cabe afirmar conclusivamente que não é o pensamento quem pensa ou o sentimento quem sente, quem assim o faz é a pessoa, que apenas arbitrária e artificialmente pode ser compartimentalizada.

Assim, materializar a unidade afetivo-cognitiva em uma ação pedagógica requer que o professor compreenda a necessária dimensão afetiva contida nos atos de caráter predominantemente pedagógico (como o ensino de regras, ensino de conteúdos escolares, ensino de comportamentos) e a necessária dimensão cognitiva contida nos atos de caráter predominantemente relacional (como a brincadeira entre educandos, as demonstrações de carinho entre educadores e educandos).

Além disso, Pasqualini e Silva (2016) alertam que as ações de cuidado dos educadores para com os educandos devem ser intencionalmente dirigidas tendo em vista a promoção do desenvolvimento infantil em suas máximas possibilidades, não devendo ser reduzidas a meras operações espontâneas. Nesse sentido, entendemos que as ações exclusivamente voltadas para a satisfação de necessidades alimentares e/ou higiênicas, bem como os cuidados mecânicos e automatizados, esvaziados de intencionalidade e trocas afetivas, negligenciam os DFC de serem cuidadas com carinho, afeto e atenção. Tais direitos estão previstos nos Artigos 17 e 18-A do ECA (BRASIL, 1990; 2017) - que dispõem, respectivamente, sobre o direito a 


\section{OO DEVIR EDUCAÇÃO}

ISSN: 2526-849X

integridade física, psíquica e moral de crianças e adolescentes e sobre o direito de serem educados e cuidados sem o uso castigos físicos - e são descritos no documento CACRDFC (CAMPOS; ROSEMBERG, 1995; 2009) como direito à atenção individual, direito a um ambiente aconchegante, seguro e estimulante, direito à higiene e saúde, direto à alimentação saudável, direito à proteção, afeto e amizade e como política de creche que preza pelo bem estar e desenvolvimento pleno da criança.

No que se refere ao direito à liberdade de expressão, respeito e valorização da diversidade étnico-cultural destacam-se algumas reflexões. Sobre o direito à liberdade de expressão e diversidade cultural, Dias (2012) traz valorosa contribuição ao demonstrar que muitas Secretarias de Educação promovem cursos sobre diversidade étnico-racial aos seus professores mas não garantem as condições necessárias para que as aprendizagens promovidas pelos cursos sejam materializadas - por exemplo, não há compra de materiais lúdicos, livros infantis, não há eventos para manifestação e celebração da diversidade, não há revisões dos documentos oficiais que busquem contemplar a diversidade étnico-racial, dentre outros.

Ciaffone e Gesser (2014) relatam uma experiência de formação continuada de educadores da EI acerca do tema "sexualidade infantil" e explicam como a formação continuada sobre esse tema levou as educadoras a repensarem e reavaliarem suas práticas e concepções acerca da expressão da sexualidade pelas crianças. Segundo elas, evidenciou-se um "estranhamento com o que estava naturalizado" (CIAFFONE; GESSER, 2014, p. 781) entre as educadoras, o que as levou a agir de modo diferente com as crianças, sendo mais respeitosas com as diferenças e assumindo uma postura de ensino sobre a diversidade ao invés da repreensão da curiosidade das crianças acerca da sexualidade. As autoras ressaltam ainda que uma prática educativa sobre sexualidade já na EI pode ajudar no processo de identificação e prevenção de situações que configuram abuso sexual e outras violências relacionadas ao corpo.

Defendemos a necessidade de uma compreensão histórica e crítica acerca da diversidade cultural, racial e sexual, uma compreensão que revele a diversidade enquanto produto histórico e, principalmente, como rico elemento constituinte do Patrimônio HumanoGenérico - e, portanto, elemento a ser estudado e apropriado por todos os seres humanos. Entendemos ainda que as características do caráter do homem (respeito/desrespeito, tolerância/intolerância, compreensão/condenação da diferença, etc.) não são inatas, outrossim, 


\section{OO DEVIR EDUCAÇÃO}

ISSN: 2526-849X

são formadas nas e pelas relações sociais estabelecidas pelos sujeitos ao longo de toda sua vida - o que nos leva a conferir ainda maior valor à escola como espaço formativo do caráter e da personalidade, sendo, portanto, espaço necessário de defesa e respeito às diferenças individuais e culturais. Para Cardoso (2016), é somente por meio de educação que respeite e valoriza a diversidade que

[...] pode-se começar construir, na criança, o valor liberdade e o respeito à dignidade de cada pessoa pela percepção de que somos diferentes na aparência, nos costumes e pensamento. A criança vai compreendendo paulatinamente que se todas as pessoas são diferentes é porque elas têm o direito de serem diferentes, de terem uma identidade própria e, portanto, elas têm o direito que serem respeitadas em sua individualidade. (CARDOSO, 2016, p. 158).

A liberdade de expressão e o respeito à diversidade - sobretudo étnico-racial, sexual e religiosa - são direitos fundamentais das crianças garantido pelos Artigos 15, 16, 17, 53 e 58 do ECA (BRASIL, 1990; 2017) - que dispõem, respectivamente: sobre o direito à liberdade e à dignidade enquanto sujeitos de diretos civis; sobre o direito à liberdade de opinião e expressão; sobre o direito a integridade física, psíquica e moral de crianças e adolescentes; sobre o direito de serem respeitados pelos educadores; e sobre o respeito aos valores culturais, artísticos e históricos de cada criança - e encontram-se também descritos no documento CACRDFC (CAMPOS; ROSEMBERG, 1995; 2009) como direito à expressão de sentimentos e direito ao desenvolvimento das identidades cultural, racial e religiosa próprias.

Sobre os direitos das crianças com deficiência e com dificuldades de aprendizagem, como já apontado, Amorim, Lima e Araújo (2017) discutem os direitos das crianças com deficiência e destacam a importância de uma formação de professores que contemple as especificidades do trabalho com Educação Especial a fim de proporcionar as máximas possibilidades de desenvolvimento às crianças com deficiência. Ao discutir as dificuldades de aprendizagem, Giroto e Castro (2011) explicam como a atribuição de rótulos às crianças pelo professor (rótulos positivos ou negativos, tais como "esperto" ou "lerdo") determina diretamente a forma de lidar e as expectativas do professor sobre o aluno (que serão maiores para os alunos "espertos" e menores para os "lerdos"). As autoras ainda destacam que atribuir rótulos a crianças em fase de alfabetização pode comprometer até mesmo a aprendizagem da 


\section{OO DEVIR EDUCAÇÃO}

ISSN: 2526-849X

linguagem escrita. As discussões empreendidas por essas estudiosas demonstram o desrespeito e aviltamento à individualidade das crianças e ao direito de aprenderem os conteúdos escolares e se desenvolverem em suas máximas possibilidades. Além disso, atitudes estigmatizantes reproduzidas pelos professores e dirigidas às crianças podem contribuir para a construção de um autoconceito e autoestima negativos nos pequenos, uma vez que há grandes possibilidades de o aluno internalizar o discurso dos professores e passar a se ver como "incapaz”, "burro", "lerdo".

Vigotski (2011) empreendeu grande dedicação ao estudo das deficiências - área de conhecimento denominada em sua época de "defectologia". Para o autor, a deficiência que impõe dificuldades e obstáculos ao desenvolvimento do sujeito é a mesma que estimula o "desenvolvimento de caminhos alternativos de adaptação, indiretos" (VIGOTSKI, 2011, p. 869). Todavia, o autor enfatiza que tais "caminhos alternativos", também chamados de "mecanismos de compensação", só se criam a partir da educação, a partir de práticas de ensino essencialmente culturais e intencionais por meio das quais torna-se possível a criação de "um sistema especial de signos ou símbolos culturais adaptados às peculiaridades da organização psicofisiológica da criança anormal" (VIGOTSKI, 2011, p. 867). Defendendo a existência de dois planos do desenvolvimento humano, dialeticamente distintos e articulados entre si, o autor russo sintetiza sua compreensão sobre deficiência na seguinte tese: "o desenvolvimento cultural [promovido pelas práticas educativas] é a principal esfera em que é possível compensar a deficiência. Onde não é possível avançar no desenvolvimento orgânico, abre-se um caminho sem limites para o desenvolvimento cultural" (VIGOTSKI, 2011, p. 869).

Sobre as dificuldades de aprendizagem das crianças sem deficiências, reiteramos o dito por Tuleski e Eidt (2007) sobre tais dificuldades resultarem, sobretudo, de organizações pedagógicas e mediações sociais insuficientes ao atendimento das necessidades de cada sujeito particular. Ao assumir como causa da dificuldade da criança um elemento estritamente genético, neurológico ou fisiológico - ou seja, ao patologizar as dificuldades da criança -, o professor encontra um respaldo pseudocientífico para justificar as falhas de sua prática de ensino e isentar-se da responsabilidade pela não aprendizagem de algumas crianças. Nesses casos, a solução mais fácil encontrada pelas instituições escolares é a medicalização de seus educandos. 


\section{OO DEVIR EDUCAÇÃO}

ISSN: 2526-849X

A Teoria Histórico-Cultural tem empreendido importante luta contra a patologização e medicalização da infância, defendendo o caráter social dos processos de ensino e aprendizagem e a importância de uma compreensão histórica sobre os determinantes sócioeconômicos que fundamentam as explicações biologizantes e patologizantes acerca das dificuldades de aprendizagem (TULESKI; EIDT, 2007). Os direitos das crianças com deficiência e/ou dificuldades de aprendizagem estão assegurados pelos Artigos 15, 17 e 54 do ECA (BRASIL, 1990; 2017) - que dispõem, respectivamente: sobre o direito à liberdade e à dignidade enquanto sujeitos de diretos civis; sobre o direito a integridade física, psíquica e moral de crianças e adolescentes; e sobre o direito ao atendimento educacional especializado - e são descritos no documento CACRDFC (CAMPOS; ROSEMBERG, 1995; 2009) como direito à atenção individual.

O direito a brincadeira e liberdade é abordado por Pinto (2006), para quem os cursos de formação de professores não fomentam discussões sobre a cultura da criança e, em especial, não discutem a importância do jogo e da brincadeira para seu desenvolvimento; quando abordam tal tema, conferem ênfase ao aspecto funcional e motor da brincadeira e não à sua potencialidade enquanto promotora do desenvolvimento psíquico dos educandos. Coadunando com essas assertivas, Leite e Carvalho (2015, p. 924) denunciam como algumas instituições de EI aprisionam, privam e limitam a infância - fenômeno denominado como "confinamento da infância" -, consolidando relações autoritárias e hierárquicas em que a sociabilidade, o desenvolvimento humano e a produção cultural perdem forças e espaços. As autoras pontuam como este tipo de funcionamento institucional é produto histórico de um modelo específico de organização social - o capitalismo.

Como brevemente discutido na introdução deste trabalho, a organização da EI deve respeitar as características específicas dos diferentes períodos do desenvolvimento infantil a fim de promover um ambiente que satisfaça as necessidades das crianças. A manipulação de objetos e o jogo protagonizado são as atividades-guia, respectivamente, da primeira infância e da idade pré-escolar, períodos em que o manipular objetos (pegar, jogar, chacoalhar, desmontar, montar, etc.) e brincar com jogos de regras implícitas (como o "faz-de-conta") ou explicitas (como jogos de tabuleiro) são imprescindíveis para a aprendizagem e humanização. Conforme explicação de Aquino (2015):

Revista Devir Educação, Lavras, vol.3, n.2, p.114-135 jul./dez., 2019. 


\section{OO DEVIR EDUCAÇÃO \\ ISSN: 2526-849X}

[...] na concepção vigotskiana, nos anos pré-escolares esse processo [de desenvolvimento] se dá predominantemente através de brincadeiras, uma vez que nos primeiros anos de vida a atividade mental ocorre via pensamento sincrético e por complexos, de forma que não opera com conceitos formais, científicos. (AQUINO, 2015, p. 42).

O documento CACRDFC (CAMPOS; ROSEMBERG, 1995; 2009) descreve a brincadeira e a liberdade como direitos das crianças e como política de creche necessária ao respeito das crianças.

$O$ direito ao desenvolvimento humano: por fim, como última categoria de nossa análise, o direito que entendemos sintetizar em si todos os demais - o direito ao desenvolvimento humano. Pinto (2006) defende a criança como ser social, inserido em um contexto social, econômico, político e cultural, defendendo, portanto, a natureza social do desenvolvimento humano. Leite e Carvalho (2015), por sua vez, definem a escola como lócus privilegiado da promoção do desenvolvimento e da socialização dos conhecimentos acumulados ao longo da história, proporcionando a autonomia e emancipação de seus alunos. Entendemos que a promoção e garantia do desenvolvimento implica, necessariamente, o respeito a todos os outros direitos discutidos ao longo deste trabalho. Promover a humanização das crianças em suas máximas possibilidades requer uma formação concreta de professores que os permita materializar uma prática teleológica, respaldada teórica e cientificamente. A intencionalidade também é dimensão essencial às ações de cuidado dirigidas às crianças, que devem satisfazer as necessidades dos pequenos tendo em vista a unidade afetivo-cognitiva essencial a cada ação (GOMES, 2014). O respeito e valorização da diversidade, incluindo o respeito às crianças com deficiência e/ou dificuldades de aprendizagem, faz-se condição indispensável à construção de uma sociedade acolhedora em que cada sujeito possa expressar livre e sem medos suas particularidades físicas e de personalidade. Promover o desenvolvimento implica, sobretudo, em uma organização pedagógica que atenda à contradição necessidade/possibilidade característica a cada período do desenvolvimento, ou seja, que compreenda a atividade principal da criança (comunicação emocional direta, atividade objetal manipulatória ou jogo de papeis) e as especificidades dos momentos críticos de transição entre períodos. Reafirmando as palavras de Vicentini e Barros (2017):

Revista Devir Educação, Lavras, vol.3, n.2, p.114-135 jul./dez., 2019. 


\section{OO DEVIR EDUCAÇÃO \\ ISSN: 2526-849X}

Na concepção Histórico-Cultural, o desenvolvimento do indivíduo está intimamente relacionado com sua relação com o outro, ou seja, na interação que se estabelece entre os sujeitos, nas atividades, nas experiências e vivências sociais, o homem se humaniza e elabora sua própria existência. (VICENTINI; BARROS, 2017, p. 169).

O direito ao desenvolvimento humano é garantido pelo Artigo 3 do ECA (BRASIL, 1990; 2017) - que dispõe sobre os direitos fundamentais de toda pessoa humana com vistas à promoção de desenvolvimento físico, mental, moral, espiritual e social - e é descrito também no documento CACRDFC (CAMPOS; ROSEMBERG, 1995; 2009) como política de creche que preza pelo bem estar físico e emocional e harmônico desenvolvimento da criança.

\section{Considerações finais}

Do corpus bibliográfico reunido, sistematizado e analisado, totalizando 11 textos, somente cinco citam diretamente algum dos direitos fundamentais das crianças. No entanto, embora não discutam o tema diretamente, acreditamos que todos os textos foram intencionalmente escritos com vistas a respeitar os direitos das crianças, de modo então que nos foi possível criar categorias de análise e refletir sobre outros DFC a partir dos ricos elementos apresentados por cada artigo. Os exemplos e discussões apresentados ora visaram defender e afirmar a importância de práticas dos profissionais da educação que respeitem os direitos das crianças e promovam desenvolvimento, ora visaram denunciar práticas que aviltam tais direitos e prejudicam o processo de humanização. Em se tratando de produções sobre formação de professores da/para a EI, compreendemos como imprescindível o comprometimento ético e científico dos educadores e o respeito e valorização ao processo educativo, às crianças e aos seus direitos.

Em relação às categorias de análise por nós criadas, buscamos organizar os elementos apresentados pelo conjunto de textos lidos e sintetizá-los a partir de eixos temáticos (categorias), para então tecer nossas defesas aos DFC à luz de uma compreensão histórica, cultural, materialista e dialética de homem, de sociedade, de desenvolvimento e de educação. 


\section{QD DEVIR EDUCAÇÃO \\ ISSN: 2526-849X}

À guisa de conclusões, reafirmamos nosso entendimento da escola, em sua essência, como espaço de ensino, aprendizagem e humanização, sendo, portanto, espaço de defesa e consolidação dos direitos das crianças. Sobre o papel do professor, o defendemos como principal mediador entre a criança e o legado material, cultural e científico humano. Em tempos de ascensão de discursos fascistas, valorização de saberes pseudocientíficos, práticas explícitas e institucionalizadas de intolerância e ódio contra quem e o que negue o padrão imposto e, sobretudo, em tempos de violentos golpes aos direitos políticos e constitucionais conquistados a duras batalhas pela organização popular, a prática educativa crítica, respaldada cientificamente e que preza pela promoção e garantia dos direitos fundamentais das crianças faz-se imprescindível à luta por uma sociedade verdadeiramente democrática e livre.

\section{Referências}

AMORIM, Gabriely Cabestré; LIMA, Elieuza Aparecida de; ARAÚJO, Rita de Cássia Tibério. Formação de professores da Educação Infantil: reflexões sobre a necessária instrumentalização teórica do profissional atuante com crianças com ou sem deficiência. Revista Ibero-Americana de Estudos em Educação, Araraquara, v. 12, n. 1, p. 387-403, jan-mar.

2017.

Disponível

em: <https://periodicos.fclar.unesp.br/iberoamericana/article/view/8867/6272>. Acesso em: 19 jul. 2019.

AQUINO, Lígia Maria Leão de. Contribuições da teoria histórico-cultural para uma educação infantil como lugar das crianças e infâncias. Fractal: Revista de Psicologia, Niterói, v. 27, n. 1, p. 39-43, jan-abr. 2015. Disponível em: <http://www.scielo.br/pdf/fractal/v27n1/19840292-fractal-27-1-0039.pdf>. Acesso em: 19 jul. 2019.

BARROS, Daniela; PEQUENO, Saulo. Cultura, Educação e desenvolvimento humano. In: COSTA, Sinara Almeida da; MELLO, Suely Amaral. Teoria Histórico-Cultural na Educação Infantil: conversando com professoras e professores. Curitiba: CRV Editora, 2017, cap. 5, p. 77-86.

BRASIL. Constituição da República Federativa do Brasil: texto constitucional promulgado em 5 de outubro de 1988, com as alterações determinadas pelas Emendas Constitucionais de Revisão nos 1 a 6/94, pelas Emendas Constitucionais n ${ }^{\text {os }} 1 / 92$ a 91/2016 e pelo Decreto Legislativo no 186/2008. Brasília: Senado Federal, Coordenação de Edições Técnicas, 1988/2016.

BRASIL. Lei de Diretrizes e Bases da Educação Nacional. Brasília: Ministério da Educação e Cultura, 1996. 


\section{OO DEVIR EDUCAÇÃO \\ ISSN: 2526-849X}

BRASIL. Lei Federal número 8.069 de 13 de julho de 1990. Estatuto da Criança e do Adolescente. Rio de Janeiro: Centro de Defesa dos Direitos da Criança e do Adolescente (CEDECA), 1990/2017.

CAMPOS, Maria Malta; ROSEMBERG, Fúlvia. Critérios para um atendimento em creches que respeite os direitos fundamentais das crianças. 6. ed. Brasília: MEC, SEB, 1995/2009.

Disponível

em:

<http://portal.mec.gov.br/dmdocuments/direitosfundamentais.pdf>. Acesso em: 19 jul. 2019.

CARDOSO, Clodoaldo Meneguello. Educação infantil em direitos humanos. In: PASQUALINI, Juliana Campregher; TSUHAKO, Yaeko Nakadakari. (Org.). Proposta Pedagógica da Educação Infantil do Sistema Municipal de Ensino de Bauru/SP. Bauru: Secretaria Municipal de Educação, 2016. p. 149-161. Disponível em: <http://www2.bauru.sp.gov.br/arquivos/arquivos_site/sec_educacao/proposta_pedagogica_ed ucacao_infantil.pdf>. Acesso em: 19 jul. 2019.

CIAFFONE, Adriane Costa e Rocha; GESSER, Marivete. Integração saúde e educação: contribuição da psicologia para a formação de educadores de uma creche em sexualidade infantil. Psicologia: Ciência e Profissão, Brasília, v. 34, n. 3, p. 774-787, Jul-set. 2014. Disponível em: <http://www.scielo.br/pdf/pcp/v34n3/1982-3703-pcp-34-03-0774.pdf>. Acesso em: 19 jul. 2019.

COUTINHO, Angela Scalabrin. As políticas para a educação de crianças de 0 a 3 anos no Brasil: avanços e (possíveis) retrocessos. Laplage em Revista, Sorocaba, v. 3, n. 1, p. 19-28, jan-abril. 2017.2 Disponível em: <http://www.laplageemrevista.ufscar.br/index.php/lpg/article/view/235/464>. Acesso em: 19 jul. 2019.

DE MARCO, Marilete Terezinha; LIMA, Elieuza Aparecida de. Docência e formação continuada de professores na Educação Infantil. Espacios, Caracas, Venezuela, v. 38, n. 45, p. 30, jun. 2017. Disponível em: <http://www.revistaespacios.com/a17v38n45/a17v38n45p30.pdf>. Acesso em: 03 jan. 2019.

DIAS, Lucimar Rosa. Formação de professores, educação infantil e diversidade étnico-racial: saberes e fazeres nesse processo. Revista Brasileira de Educação, Rio de Janeiro, v. 17, n. 51, p. 661-674, $\quad$ set-dez. 2012. Disponível em: <http://www.redalyc.org/articulo.oa?id=27524689010>. Acesso em: 19 jul. 2019.

FACCI, Marilda Gonçalves Dias. A periodização do desenvolvimento psicológico individual na perspectiva de Leontiev, Elkonin e Vigotski. Caderno Cedes, Campinas, v. 24, n. 62, p. 64-81, abril. 2004. Disponível em: <http://www.scielo.br/pdf/ccedes/v24n62/20092.pdf>. Acesso em: 20 jul. 2019.

FEBRONIO, Maria da Paixão Gois. Formação inicial de professores de educação infantil: que formação é essa? Educação Temática Digital, Campinas, v. 12, n. 2, p. 151-171, jan-jun. 2011.

<https://periodicos.sbu.unicamp.br/ojs/index.php/etd/article/view/1194/pdf >. Acesso em: 19 jul. 2019. 
GIROTO, Claudia Regina Mosca; CASTRO, Rosane Michelli de. A formação de professores para a Educação Inclusiva: alguns aspectos de um trabalho colaborativo entre pesquisadores e professores da Educação Infantil. Revista de Educação Especial, Santa Maria, v. 24, n. 41, p. 441-452, Set-Dez. 2011. Disponível em: <https://periodicos.ufsm.br/educacaoespecial/article/view/3106/2701>. Acesso em: 19 jul. 2019.

GOMES, Cláudia Aparecida Valderramas. A relação sujeito-objeto e a unidade afetivocognitiva: contribuições para a Psicologia e para a Educação. Revista Quadrimestral da Associação Brasileira de Psicologia Escolar e Educacional, São Paulo, v. 18, n. 1, p. 161168, Jan-Abr. 2014. Disponível em: 〈http://www.scielo.br/pdf/pee/v18n1/v18n1a17.pdf>. Acesso em: 24 nov. 2019.

GUIMARÃES, Daniela de Oliveira; ARENHART, Deise; SANTOS, Nubia de Oliveira. Educação Infantil pós-LDB/1996: formação inicial de professores e práticas pedagógicas. Revista Contemporânea de Educação, Niterói, v. 12, n. 24, p. 362-379, maio-agosto. 2017. Disponível em: <https://revistas.ufrj.br/index.php/rce/article/view/4171/pdf_1>. Acesso em: 19 jul. 2019.

LEITE, Sandra Regina Mantovani; CARVALHO, Alonso Bezerra de. Formação de professores para a Educação Infantil: a integração necessária entre educação e cuidado para uma práxis pedagógica emancipatória. Revista Ibero-Americana de Estudos em Educação, Araraquara, v. 10, n. 3, p. 917-931, jul-set. 2015. Disponível em: <https://periodicos.fclar.unesp.br/iberoamericana/article/view/8100/5505>. Acesso em: 19 jul. 2019.

MARTINS, Lígia Márcia. Formação de professores: desafios contemporâneos e alternativas necessárias. In: MENDONÇA, Sueli Guadalupe de Lima; SILVA, Vandeí Pinto da; MILLER, Stela. (Org.). Marx, Gramsci e Vigotski: aproximações. Araraquara: Junqueira e Marin, 2009. p. 449-472.

MARTINS, Lígia Márcia. O Desenvolvimento do Psiquismo e a Educação Escolar: contribuições à luz da psicologia histórico-cultural e da pedagogia histórico-crítica. 2011. p. 250. Tese (Livre-docência em Psicologia da Educação). Universidade Estadual Paulista "Júlio de Mesquita Filho", Bauru, 2011. Disponível em: $<$ https://formacaodocente.files.wordpress.com/2012/09/martins_ligia__o_desenvolvimento_do_psiquismo_e_a_educacao_escolar.pdf $>$. Acesso em: 24 nov. 2019.

MENDONÇA, Fernando Wolff. A organização da atividade de ensino como processo formativo do professor alfabetizador: contribuições da Teoria Histórico-Cultural. 2017. p. 247.Tese (Doutorado em Educação) - Universidade Estadual de Maringá, Maringá, 2017. Disponível em: <http://www.ppe.uem.br/teses/2017/2017\%20-\%20Fernando\%20Wolff.pdf〉. Acesso em: 19 jul. 2019.

OLIVEIRA, Joana Angélica Bernardo de. Formação de professores, competências e saberes para a atividade docente na Educação Infantil. Revista Ibero-Americana de Estudos em Educação, Araraquara, v. 1, n. 1, p.113-122, Jan-Mar. 2006. Disponível em: 


\section{OO DEVIR EDUCAÇÃO \\ ISSN: 2526-849X}

<https://periodicos.fclar.unesp.br/iberoamericana/article/view/436/316>. Acesso em: 19 jul. 2019.

PASQUALINI, Juliana Campregher. Concepção de homem, educação e desenvolvimento. In: PASQUALINI, Juliana Campregher; TSUHAKO, Yaeko Nakadakari. (Org.). Proposta Pedagógica da Educação Infantil do Sistema Municipal de Ensino de Bauru/SP. Bauru: Secretaria Municipal de Educação, 2016. p. 41-68. Disponível em: <http://www2.bauru.sp.gov.br/arquivos/arquivos_site/sec_educacao/proposta_pedagogica_ed ucacao_infantil.pdf>. Acesso em: 19 jul. 2019.

PASQUALINI, Juliana Campregher; SILVA, Célia Regina da. Cuidar e educar na escola de educação infantil. In: PASQUALINI, Juliana Campregher; TSUHAKO, Yaeko Nakadakari. (Org.). Proposta Pedagógica da Educação Infantil do Sistema Municipal de Ensino de Bauru/SP. Bauru: Secretaria Municipal de Educação, 2016. p. 567-572. Disponível em: $<$ http://www2.bauru.sp.gov.br/arquivos/arquivos_site/sec_educacao/proposta_pedagogica_ed ucacao_infantil.pdf>. Acesso em: 19 jul. 2019.

PEREIRA, Meira Chaves. A formação continuada de professores da educação infantil em Sorocaba/SP. Laplage em Revista, Sorocaba, v. 3, n. 3, p. 190-199, set-dez. 2017. Disponível em: <http://www.laplageemrevista.ufscar.br/index.php/lpg/article/view/366/595>. Acesso em: 19 jul. 2019.

PINTO, Rúbia-Mar Nunes. A formação de professores para a Educação Infantil: desafios para a universidade. Pensar a Prática, Goiânia, v. 4, p. 135-148, 2006. Disponível em: <https://revistas.ufg.br/fef/article/view/82/80>. Acesso em: 19 jul. 2019.

SOUZA, Neusa Maria Marques de; MOURA, Manoel Oriosvaldo de. Integração escolauniversidade como atividade de formação continuada de professores na perspectiva históricocultural. Perspectivas da Educação Matemática, Campo Grande, v. 8, n. 16, p. 140-165, ago. 2015. Disponível em: <http://seer.ufms.br/index.php/pedmat/article/view/944/912>. Acesso em: 21 fev. 2019.

TONINATO, Tatiane Dalpério. Formação identitária dos professores de Educação Infantil: compreensão acerca do trabalho docente. Revista Ibero-Americana de Estudos em Educação, Araraquara, v. 1, n. 2, p. 182-192. 2006. Disponível em: $<$ https://periodicos.fclar.unesp.br/iberoamericana/article/view/444/323>. Acesso em: 19 jul. 2019.

TULESKI, Silvana Calvo; EIDT, Nádia Mara. Repensando os distúrbios de aprendizagem a partir da psicologia histórico-cultural. Psicologia em Estudo, Maringá, v. 12, n. 3, p. 531540, set-dez. 2007. Disponível em: 〈http://www.scielo.br/pdf/pe/v12n3/v12n3a10.pdf〉. Acesso em: 19 jul. 2019.

VICENTINI, Dayanne; BARROS, Marta Silene Ferreira. A humanização da criança na educação infantil: implicações da teoria histórico-cultural. Educação, Santa Maria, v. 42, n. 1, p. 163-176, jan-abr. 2017.20 Disponível em: <https://periodicos.ufsm.br/reveducacao/article/view/23681/pdf>. Acesso em: 19 jul. 2019. 
VIGOTSKI, Lev Semionovitch. A defectologia e o estudo do desenvolvimento e da educação da criança anormal. Trad. Denise Regina Sales, Marta Kohl de Oliveira e Priscila Nascimento Marques. Educação e Pesquisa, São Paulo, v. 37, n. 4, p. 861-870, dez. 2011. Disponível em: <http://www.scielo.br/pdf/ep/v37n4/a12v37n4.pdf>. Acesso em: 19 jul. 2019. 